\title{
Enfermedad, identidad y simbolismo en Salón de belleza, de Mario Bellatin
}

\author{
Paula RodríGUez-AbruñeIRAS \\ University of Wisconsin-Milwaukee \\ rodri423@uwm.edu
}

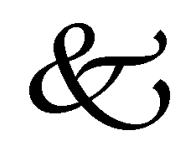

\begin{abstract}
Resumen
Salón de belleza (1994), de Mario Bellatin, podría considerarse como un retrato de la soledad en grado extremo. La novela cuenta en primera persona la historia de un antiguo salón de belleza reconvertido en Moridero, es decir, en un lugar donde enfermos terminales van a pasar sus últimos días. La falta de identidad y el anonimato reinan de principio a fin, y solo en el tratamiento de los peces el narrador se recrea. Este narrador se comporta como un pequeño dios que toma decisiones y condiciona el futuro de los enfermos, sin importarle demasiado lo que estos puedan pensar o sentir. En la lectura de la novela, tres aspectos se revelan como primordiales: el simbolismo que los peces adquieren en la narración, la enfermedad que avanza de forma imparable y el tratamiento de la identidad (individual y colectiva) que se va trazando de la mano de estos otros dos aspectos.
\end{abstract}

Palabras claves: Mario Bellatín, Salón de belleza, identidad, simbolismo.

\begin{abstract}
Beauty salon (1994) of Mario Bellatin, could be seen as a portrait of loneliness. The novel tells the story of a former salon turned into a dying place, id est, in a place where terminally ill patients will spend their last days. The lack of identity and anonymity reign from beginning to end. The narrator behaves like a little god who makes decisions and determines the future of the sick, not caring too much what they may think or feel. In reading the novel, three aspects are revealed: the symbolism of the fish, the disease progresses unabated and the treatment of identity (individual and collective) to be drawing hand these two aspects.
\end{abstract}

Keywords: Mario Bellatín, Beauty Salon, identity, symbolism.

Recibido: 11/10/14 Aceptado: 2/12/14 Publicado on line: 10/2/15 


\section{Los peces y su simbolismo en Salón de belleza}

La carga alegórica de los peces en Salón de belleza es tal que por momentos el límite ente lo animal y lo humano se desdibuja en la obra. El papel tan central de los peces queda patente desde el primer párrafo, donde el narrador describe minuciosamente su afición por estos animales, relegando la narración de su enfermedad -al menos por un momento- a un segundo plano. Esta estrategia es utilizada por Bellatin para alejarse "del tono trágico esperado y la reflexión moral cuando se aborda el tema de la muerte propia y ajena” (Sáenz y López 37). De hecho, todo lo relacionado con los peces recibe en Salón de belleza una atención extrema. A lo largo de la historia, el narrador nos detalla una a una todas las clases de peces que ha tenido en el salón y, posteriormente, en el Moridero: Gupis Reales, Carpas Doradas, Ajolotes, Monjitas, Escalares, Peces Peleadores, Peces Basurero, Pirañas Amazónicas y Peces Lápiz se encuentran entre sus múltiples adquisiciones. Se podría decir que los peces tienen una identidad mucho más perfilada y definida que cualquier otro elemento de la novela. Esto se evidencia especialmente si los comparamos con las personas: ninguno de los personajes tiene nombre propio, ni siquiera el narrador, y sin embargo sí tenemos una lista considerablemente extensa de razas de peces. No solo eso, el narrador es el único que tiene una historia, mientras que los demás parecen ser meros figurantes que sirven de excusa para la existencia del Moridero pero cuya historia personal y cuyo mundo interior no importan.

Se podría afirmar que Salón de belleza narra una historia en construcción ya que el autor comienza in media res, esto es, no hay un principio, un desarrollo y un fin como tal, sino que se nos introduce en el mundo del narrador cuando ya su enfermedad se encuentra en un estado avanzado y él hace memoria para recordar sus tiempos de gloria en el pasado (véase Sáenz y López 39). Todo en la historia parece estar en progreso constante, especialmente el avance incesante de la enfermedad. En este sentido, los peces también sufren una continua mutación. Así, no es fortuito que cuando el narrador descubre su afición por los peces se decante por aquellos que poseen colores llamativos y que aportan alegría y jovialidad al Salón. Su primera adquisición son Gupis Reales, peces resistentes y de gran colorido. Posteriormente se atreve con las Carpas Doradas, y aunque se plantea comprar Goldfish, finalmente rechaza esta idea por considerarlos "lerdos, casi estúpidos" (Bellatin 29). Sin embargo, hacia el final de la novela, este colorido va desapareciendo y deja paso a peces más oscuros, resistentes y agresivos como las Monjitas, las Pirañas Amazónicas y los Ajolotes.

La relación del narrador con los peces también evoluciona a lo largo de la historia. En un principio, los peces son una fuente de satisfacción y deleite para el narrador, quien se sorprende al ver cómo estos "pueden influir en el ánimo 
de las personas" (Bellatin 28). De hecho muestra una gran simpatía por las Carpas Doradas, las cuales afectaron notablemente su manera de vestir ya que en la época en que tenía estos peces se animaba a llevar alguna prenda dorada cuando salía por las noches. No obstante, a medida que avanza la trama, el narrador se vuelve más negligente en el cuidado de los peces y es consciente del abandono al que está condenando a los que en su momento fueran objeto de su admiración (y, en cierto sentido, de su obsesión). En los últimos días del Moridero ya no se preocupa por limpiar la pecera, que luce ahora un tono verdoso y contiene agua sucia. Su comportamiento con los peces se vuelve cruel por momentos ya que le gusta experimentar con sus reacciones aun cuando ello implica despertar su instinto caníbal (véase Quintana 492). Esto se ve, por ejemplo, cuando deja a los Ajolotes con los Peces Basurero a sabiendas de que estos van a ser devorados (véase Bellatin 45-46).

Cuando el narrador habla de los Ajolotes los describe como "peces que parecen estar a mitad del camino de la evolución” (Bellatin 45). Se podría ver en esta caracterización una alusión al propio estado del narrador y de los demás enfermos, quienes en efecto se encuentran inmersos en un proceso de evolución (o quizás el término involución sería más apropiado), de transformación constante que los arrastra de forma inevitable hacia la muerte. En ocasiones, el propio narrador es quien compara el mundo de los peces con su mundo. Así, por ejemplo, establece un paralelismo entre los baños de vapor y la pecera, y reconoce que en los baños "siempre me sentía como si estuviera dentro de uno de mis acuarios", sobre todo al presenciar "la persecución de los peces grandes cuando buscaban comerse a los más pequeños" (Bellatin 30). Este paralelismo se vuelve más evidente cuando el narrador hace una comparación explícita entre los peces y los enfermos, ya que dice de estos que "se aferran a la vida igual que los Gupis de la última camada" (Bellatin 35). Se podría encontrar también una alusión metafórica en la descripción de las peceras. Así pues, en un principio el narrador quería que su salón contara con peceras de gran tamaño para que "las clientas tuvieran la sensación de encontrarse sumergidas en un agua cristalina para luego salir rejuvenecidas y bellas a la superficie" (Bellatin 33). De hecho, la primera pecera que compra mide dos metros de largo. De acuerdo con Delgado, "no es coincidencia que las dimensiones de este primer acuario coincidan con las de un féretro, dato que infunde un tono funerario a la sumersión simbólica de las clientas en el salón” (Delgado 78). Aunque, paradójicamente, los féretros tampoco son muy comunes en el Moridero ya que, una vez muertos, los cuerpos de los enfermos van a parar a una fosa común, con la única excepción del joven con el que el narrador tuvo un acercamiento afectivo. En cualquier caso, la mayoría de las peceras que en su momento contenían peces alegres y aportaban vitalidad al 
entorno, al final de la novela solo sirven para guardar las pertenencias de los enfermos, a excepción de una en la que todavía conserva algunos peces que suponen la principal fuente de vida del Moridero.

\section{El sida en Salón de belleza}

\subsection{Enfermedad como negación de la identidad}

La enfermedad es el hilo conductor de la historia narrada en Salón de belleza y la razón por la cual esta existe. Su presencia lo impregna todo, incluso al lector, quien no puede evitar sentir una sensación de desasosiego y angustia a medida que la trama avanza y la enfermedad se apodera de los cuerpos en los que habita. Bellatin logra este efecto mediante el uso de un lenguaje preciso y sobrio y un estilo sencillo y minucioso, desprovisto de adjetivación pero cargado de imágenes sensoriales que apelan al sentimiento del lector y buscan su reacción: "hay gemidos, olores, hedor, presencia de fluidos corporales de ampollas, pústulas y heridas" (Sáenz y López 38). Pese a todo, cabe destacar que en ningún momento se identifica la enfermedad a la que tantas veces se alude. Varias son las formas en que esta aparece denominada: el mal, la enfermedad, la peste; se habla de "cuerpos en trance hacia la desaparición” (Bellatin 33) o, de forma más eufemística, el narrador dice de sus compañeros del Salón que "los dos murieron de lo mismo" (Bellatin 35), pero sin aclarar de qué. No obstante, sí se puede identificar tal enfermedad como sida "por sus síntomas, formas de contagio y estigma social" (Guerrero 67). El hecho de no mencionar la palabra sida parece ser una práctica común en la literatura existente sobre el tema, tal y como apunta Jones: "Many authors have created stories in which gay men have AIDS; yet, surprisingly, the name AIDS is not often mentioned" (228). La omisión deliberada del nombre de la enfermedad tiene como resultado que "quienes cobran agencia son los cuerpos enfermos, no la enfermedad” (Guerrero 89). Esto no haría más que confirmar lo que varios autores han apuntado sobe la atención inusitada que Bellatin concede al cuerpo en su obra (véase Amato 35 o Guerrero 63, entre otros). El cuerpo, en cualquier caso, avanza hacia un estado de descomposición en la novela. El narrador cosifica estos cuerpos y les niega el derecho a cualquier ápice de identidad: "Puede parecer difícil que me crean, pero ya casi no individualizo a los huéspedes. Ha llegado un estado en el que todos son iguales para mí. Al principio los reconocía. Incluso una que otra vez llegué a encariñarme con alguno. Pero ahora no son más que cuerpos en trance hacia la desaparición" (Bellatin 33). Cuando narra su acercamiento afectivo a uno de los enfermos añade: "De un momento a otro dejó de interesarme por completo...Casi al instante el mal lo atacó con violencia. No tardó en morir... Para ese entonces, el cuerpo del muchacho sólo significaba un cuerpo más al que había la obligación de eliminar" (Bellatin 34). 
El narrador de Salón de belleza regenta el Moridero a su antojo y capricho (véase Epplin 105), con una serie de normas estrictas y excluyentes que, por lo general, no se salta nunca. Así, las mujeres no son aceptadas en el Moridero; más aún, se muestra impasible ante las súplicas de mujeres que quieren alojarse en esta comunidad que él mismo creó. La negativa a la admisión del género femenino es ciertamente sorprendente, sobre todo si tenemos en cuenta que eran ellas las que acudían al Salón cuando este era un lugar destinado a la belleza y no a la muerte. Ahora, sin embargo, no son admitidas en el Moridero, pese a que, en cierto modo, la diferencia entre un cuerpo masculino y un cuerpo femenino afectados por la enfermedad se vuelve difusa. Guerrero afirma al respecto: "la oposición masculino-femenino -ya inestable en el salón de belleza- reafirma su disolución en el Moridero, al borrarse, deshacerse las marcas sexuales de los huéspedes a causa de la enfermedad letal" (Guerrero 70). De hecho, los enfermos que son admitidos en el Moridero se encuentran en un estado de "muerte simbólica" dado que "sus cuerpos sobreviven biológicamente a pesar de que sus otras cualidades y capacidades vitales se han extinguido" (Amato 59). Se puede considerar, por lo tanto, que "el moridero funciona como antesala de la muerte, el ingreso a este espacio supone la pérdida de la identidad, del nombre propio y del ingreso a una temporalidad en la que se suspende, simultáneamente, la posibilidad de todo pasado y de todo futuro" (Vaggione 482). Lo único que puede hacer el enfermo en el Moridero es esperar la llegada de la muerte, rindiéndose sin luchar por su salvación, y aceptar resignado que el sufrimiento y la muerte son parte de la vida. La muerte es, en definitiva, el final de la agonía y del sufrimiento.

\subsection{El sida y el sentimiento de culpa}

En términos generales, la enfermedad siempre se ha visto relacionada con el pecado y la culpa. Simonet (63-64) hace memoria histórica y alude a varias plagas que han afectado a la humanidad durante siglos. En su análisis se pone de manifiesto el cambio de implicación que dichas plagas han traído según cada momento histórico. Así, mientras que en la Edad Media se consideraba que las enfermedades eran castigos divinos, en el Romanticismo la tuberculosis parecía ciertamente ennoblecer a quien la padecía, mientras que en la actualidad algunas enfermedades (especialmente el sida) conllevan nuevamente un sentimiento de culpa. Sontag compara el sida con el cáncer, y aporta una diferencia importante entre ambas: el cáncer se ha visto tradicionalmente como algo bochornoso para el paciente, quien se pregunta por qué le ha tocado a él sufrir la enfermedad (véase Sontag 24). En el caso del enfermo de sida, al bochorno hay que sumar el sentimiento de culpabilidad 
ocasionado por el escándalo que acompaña a este mal. El sida es, de hecho, "la enfermedad por excelencia de la culpa, del castigo merecido, relacionada con el pecado de lujuria y marginalidad social y sexual" (Simonet 65). El estigma social se debe principalmente a que el sida se relaciona con un grupo de riesgo que ha llevado a cabo una conducta sexual reprochable ante los ojos de la sociedad. Algunos de los principales grupos de riesgo son los homosexuales, las prostitutas (cf. Davies et al. 42) y los consumidores de drogas (cf. Jones 225), pero eso no quiere decir que los demás sectores de la sociedad estén libres de verse afectados por el sida. De hecho, hoy en día sabemos que cualquier persona -independientemente de su edad, sexo, clase social o condición sexual- puede contraer el sida si lleva a cabo prácticas sexuales sin protección. Es por esto que parece haber una opinión generalizada de que "quien contrae sida lo hace por voluntad, y lo que tal vez fue un descuido se transforma ante la mirada de la sociedad como una suerte de suicidio" (Simonet 65). En la novela, el hecho de que los enfermos carezcan de identidad y se presenten como parte de un grupo parece acentuar esta idea de enfermedad como castigo a un sector de riesgo. No obstante, en cierto modo esto entraría en contradicción con la actitud del narrador de no emitir juicios de valor: este en ningún momento juzga a los enfermos, sino que se mantiene objetivo y neutro con respecto a lo que narra. Por eso, pese a que la historia está contada en primera persona, parece estar narrada desde la distancia.

Cuando un enfermo descubre que ha contraído el sida suele producirse un cambio significativo en su vida sexual, aunque dicho cambio se puede manifestar, de acuerdo con Franzini (81), en dos direcciones. Por un lado, es posible que el enfermo opte por tener el máximo número posible de relaciones sexuales mientras todavía sea aceptado por los demás. Por otro, puede que el enfermo se abstenga de practicar sexo de nuevo. En cuanto al caso concreto del narrador de Salón de belleza, una vez su enfermedad avanza y ya es imposible esconder sus efectos sobre su cuerpo, resuelve terminar con su vida alegre y jovial del pasado. Así, decide quemar en una fogata la ropa con la que se solía travestir, poniendo punto y final de forma consciente a una etapa de su vida, a una dicotomía constante que lo llevaba a ser incapaz de definir su identidad masculina o femenina. Por ello, en cierto modo la aparición de la enfermedad aporta tranquilidad y estabilidad a su vida ya que a raíz de esta el protagonista abandona la juerga y el travestismo. En el pasado, al vestirse de mujer se había movido entre dos mundos, el masculino y el femenino, pero la enfermedad pone fin a dicho dilema, concediéndole así una personalidad más estable. No obstante, tener que abandonar una actividad que le aportaba tanta felicidad "obstaculiza . . . la búsqueda de identidad" (Simonet 72). En este sentido, "el sujeto se va alejando de sí mismo: es cuando el individuo asiste impotente 
a la pérdida de su dimensión subjetiva que se da el primer paso hacia la desaparición final" (Simonet 73).

El fuego toma cierta relevancia en la novela al aparecer con una gran carga simbólica en diversas ocasiones. Se ha mencionado ya brevemente que el protagonista decide quemar su ropa para despojarse así de su pasado. Además, los vecinos introducen el elemento del fuego cuando se acercan al Moridero para intentar quemarlo, acto que el narrador interpreta como un símbolo de purificación ante un mal que, para muchos, significa contaminación. La cruzada que emprenden los vecinos contra el Matadero y todos los que en él habitan se debe, probablemente, al miedo a un posible contagio, lo cual "refleja mucha ignorancia y representa la victoria de los prejuicios sin fundamento sobre el sentido científico" (Simonet 66). Como apunta Sontag, esta reacción es común ante una enfermedad como el sida: "Infectious diseases to which sexual fault is attached always inspire fears of easy contagion and bizarre fantasies of transmission by nonveneral means in public places" (Sontag 27). Por otro lado, el propio narrador menciona el fuego como posible solución cuando reflexiona sobre el futuro del Moridero una vez él no esté. Se plantea quemar el edificio con todo y todos los que en él se encuentren, aunque finalmente rechaza esa idea porque le parece que sería una solución demasiado fácil. Se podría interpretar que esta actitud del narrador contiene un cierto tono nihilista, aunque Mora se opone a esta interpretación: "La obra de Bellatin no es nihilista, no plantea la nada y la destrucción como solución de las cosas, quizá por la predisposición espiritual del propio autor, pero sí es fatalista; sí cree que todo lo tocante al hombre es impuro y putrefacto por naturaleza" (Mora 85).

Llegados al final de la novela, el narrador recapacita y considera que el futuro más justo para el Moridero es el de volver a sus orígenes y convertirse de nuevo en Salón de belleza, aunque solo en apariencia. Parece así que pretende eliminar cualquier tipo de vestigio, evidencia o huella del paso de la enfermedad por aquellas paredes. De nuevo sueña con experimentar con el sufrimiento de los peces, a los que planea dejar asfixiándose en un descampado de forma muy similar a como los enfermos de sida se mueren en el Moridero sin la ayuda de los medicamentos.

\section{Conclusiones}

Uno de los aspectos más interesantes de Salón de belleza es el anonimato tan patente que lo impregna todo, lo que hace que la novela tenga una deliberada aplicación universal. En ningún momento se nos dice dónde transcurre la acción, ni se nombra la enfermedad, ni mucho menos se identifica a los personajes. La falta de concretización queda patente cuando todo enfermo que entra en el 
Moridero pasa a formar parte de un grupo en decadencia y descomposición. Las normas rígidas e inamovibles impuestas por el narrador niegan el acceso a mujeres en cualquier estado y a hombres que todavía no muestran síntomas evidentes de la enfermedad. No obstante, la caracterización es mucho más concreta cuando se refiere a los peces, que tienen un gran peso en la historia y de los que se hace una descripción detallada y minuciosa. Los peces y todo lo relacionado con ellos tienen un papel alegórico a lo largo de la historia: los peces infectados representan a los enfermos terminales, su muerte es una alegoría clara de la muerte de los enfermos, el acuario descuidado representa el estado de ánimo del narrador y su propio abandono y las peceras vacías no hacen más que aludir a la ausencia de clientas en el Salón y, en general, de vida, pues los cuerpos que allí habitan tienen más rasgos de muertos que de vivos.

Bellatin consigue transformar en su obra algo en apariencia frívolo e intrascendente como es un salón de belleza en el escenario ideal para una reflexión sobre la condición humana, especialmente sobre la decadencia de la misma. El hecho de no llegar a mencionar la palabra sida hace pensar al lector que la enfermedad incurable que se nos pinta es la propia muerte, independientemente de la forma que esta toma pero a la que estamos sentenciados todos desde el momento mismo de nuestro nacimiento. La actitud del narrador de Salón de belleza sería, por tanto, la de embellecer y disfrutar de nuestros cuerpos mientras estén llenos de vida, pero aceptar la muerte con dignidad cuando esta empieza a asomarse.

\section{Referencias bibliográficas}

AMATO, M. (2012) “La vida en el umbral, una poética”. En J. Ortega \& L. Dávila (Eds.) La variable Bellatin. Navegador de lectura de una obra excéntrica.). Veracruz: Universidad Veracruzana; pp. 35-70

BELLATIN, M. (1994). "Salón de belleza” en Obra reunida México: Alfaguara; pp. 27-53.

DAVIES, P.M., Hickson, F., Weatherburn, P., \& Hunt., A.J. (1993) Sex, Gay Men and AIDS. Londres: The Falmer Press.

DELGADO, S. (2011) "Estética, política y sensación de la muerte en Salón de belleza de Mario Bellatin” en Revista Hispánica Moderna, 64(1); pp. 69-79.

EPPLIN, C. (2012) “Mario Bellatin y los límites del libro”. En J. Ortega \& L. Dávila (Eds.) La variable Bellatin. Navegador de lectura de una obra excéntrica. Veracruz: Universidad Veracruzana; pp. 99-117.

FRANZINI, L.R. (1993) "The Paradox of Accurate Information Increasing the Fear of AIDS”. En S.C. Ratzan (Ed.) Effective Health Communication for the 90s. Washington: Taylor and Francies; pp.71-90.

GUERRERO, J. (2009) “El experimento "Mario Bellatin”. Cuerpo enfermo y anomalía en el tránsito material del sexo" en Estudios. Revista de Investigaciones Literarias y Culturales 17 (33); 63-96. 
JONES, J.W. (1993) "Refusing the Name: The Absence of AIDS in Recent American Gay Male Fiction”. En T.F. Murphy \& Suzanne Poirier (Eds.) Writing AIDS: Gay Literature, Language, and Analysis Nueva York: Columbia UP. ; pp. 225-243.

MARTINETTO, V. (2012) "Palimpestos en el universo Bellatin". En J. Ortega \& L. Dávila (Eds.) La variable Bellatin. Navegador de lectura de una obra excéntrica. Veracruz: Universidad Veracruzana; pp.15-33.

MORA, V.L. (2012) "Las mutaciones mórbidas: el espejo y la muerte en la obra de Mario Bellatin”. En J. Ortega \& L. Dávila (Eds.) La variable Bellatin. Navegador de lectura de una obra excéntrica. Veracruz: Universidad Veracruzana; pp. 71-98.

ORTEGA, J. \& Lourdes, D. eds. (2012) La variable Bellatin. Navegador de lectura de una obra excéntrica. Veracruz: Universidad Veracruzana.

QUINTANA, I.A. (2009) "Escenografía del horror: Cuerpo, violencia y política en la obra de Mario Bellatin” en Revista Iberoamericana 75 (227); pp.487-504.

RUBIO, L. (2009) "De la vanidad a la agonía: El grotesco de Bajtín en Salón de belleza de Mario Bellatin" en Espéculo. Revista de Estudios Literarios 40. https://pendientedemigracion.ucm.es/info/especulo/numero40/salonbe.html.

SÁENZ, I. (2012) "Hacer zapping de sí mismo: Bellatin y el yo hipermoderno". En J. Ortega \& L. Dávila La variable Bellatin. Navegador de lectura de una obra excéntrica. Veracruz: Universidad Veracruzana ;pp. 135-162.

SÁENZ, I. \& López, R. (2005) “Demonizar a Bellatin: Las transgresiones de Salón de belleza” en Revista de Literatura Mexicana Contemporánea 2 (26); pp. 36-40.

SIMONET, V.P. (2009) "Enfermedad e identidad en Salón de belleza, de Mario Bellatin" en Revista de literatura mexicana contemporánea 16(41);pp. 63-73.

SONTAG, S. (1989). AIDS and Its Metaphors. Nueva York: Farrar, Straus and Giroux.

VAGGIONE, A. (2009) "Literatura/enfermedad: El cuerpo como desecho. Una lectura de Salón de belleza de Mario Bellatin” en Revista Iberoamericana 57(227); pp. 475-486. 
